\title{
The Perspectives of Males with Serious Mental Disorders on their Community Integration following a Residential-based Rehabilitation Programme in South Africa: "It's a catch-22 situation"
}

\author{
*Fadia Gamaldien; BSc OT (UCT), MSc OT (UCT). https://orcid.org/0000-0003-2820-6484 \\ Senior Clinical Educator, Division of Occupational Therapy, Department of Health and Rehabilitation, University of Cape Town, Cape Town.
}

Roshan Galvaan; BSc OT (UCT), MSc OT (UCT), PhD (UCT). https://orcid.org/0000-0003-00 I4-1842

Professor, Division of Occupational Therapy, Inclusive Practices Africa Research Unit, Department of Health and Rehabilitation Sciences, University of Cape Town, Cape Town.

\author{
Madeleinde Duncan; Dip OT (UP), BOT(UOFS), BA Hons (Psych) (UDW), MSc OT (UCT), D Phil Psych (US). \\ https://orcid.org/0000-0002-5359-8849 \\ Emeritus Associate Professor, Division of Occupational Therapy, Department of Health and Rehabilitation Sciences, University of Cape \\ Town, Cape Town, South Africa.
}

\begin{abstract}
Introduction: Residential-based rehabilitation programmes were introduced by the Western Cape Department of Health in 2008 to relieve the burden of long-term hospitalization in South Africa. In South Africa, more men than women of working age require long-term support from public mental health services. Most of these healthcare users live in communities characterised by poverty and unemployment. There is limited research on male mental health service users' perspectives on the impact that residential-based rehabilitation programmes have on their community integration. The aim of the study was to inform the continuum of care for people with serious mental disorders to better align residential-based rehabilitation and primary care public mental health services with the recovery needs of mental health service users.

Method: An instrumental case study design was applied, and five male participants were identified through purposive sampling. Observations, semi-structured interviews, community maps and document analysis were used to collect data. Thematic cross-case analysis of qualitative data was done.

Findings: The theme, It's a catch-22 situation, describes the participants' ambivalence towards the residential-based rehabilitation programme's contribution to their community reintegration after discharge. Three categories, namely 'It's not just what you call it', 'There's no one size for all', and 'It's tricky choosing between places to go and things to do', capture how the perceived inflexibility of the programme curtailed their adjustment to community living.

Conclusion: Participants proposed co-constructing their recovery plan with mental health professionals so that it is more personalised in supporting them as they adapt to emergent occupational challenges. It is recommended that a seamless continuum of support between different levels of care should be implemented.
\end{abstract}

Key words: community integration, rehabilitation, serious mental disorders, recovery, mental health service users.

\section{INTRODUCTION}

Serious mental disorders (SMDs) are significant contributors to the world's disease burden and a leading cause of years lived with disability'. SMDs include schizophrenia spectrum disorders, schizoaffective disorders, bipolar affective disorders, major depressive disorders and related psychotic disorders (schizophreniform, delusional disorder, substance-induced psychotic disorder or disorders not otherwise specified) and co-morbid substance use disorder ${ }^{1,2}$. The usual onset of SMDs occurs in young adulthood with a lifetime prevalence ranging between I and $4 \%{ }^{3}$. Adverse societal costs impacting on people with SMD include low educational achievement, marital instability, decreased financial status and stigma ${ }^{4-6}$

The persistent and fluctuating symptoms associated with SMDs influence the frequency of hospital admissions, extent and rate of clinical and personal recovery and level of community integration that can be attained by mental health service users (MHSUs). Community integration refers to the ability of a person with an SMD to live, work and enjoy their free time and day-to-day activities within a community setting as part of their recovery journey ${ }^{7}$. Clinical recovery focusses on symptom reduction for improved functioning through bio-psycho-social treatment ${ }^{8}$. Personal recovery is "a deeply personal, unique process of changing ones' attitude, values, feelings, goals, skills and/or roles. It is a way of living a satisfying, hopeful and contributing life despite the limitations caused by illness"9:15. Personal recovery unfolds alongside clinical recovery and involves the development of identity beyond the assigned label of mentally ill patient ${ }^{8}$. 
The process of recovery from an SMD is cyclical and unique to each person ${ }^{10}$. Acute episodes of SMD may require tertiary level hospitalization for specialist psychiatric care. Once the person is medically stable, an intermediary period of residential-based rehabilitation may be indicated to equip MHSUs with strategies for coping with community integration after discharge. Out-patient follow-up is provided at a community health centre $(\mathrm{CHC})$ close to where the person lives. The focus of services at the primary level of care is on the maintenance of clinical recovery, the prevention of relapse and the promotion of personal recovery through supported community integration ${ }^{4, ~} 1$. Support is provided by district mental health teams including occupational therapists, in collaboration with community health workers and should in principle be aligned with the inter-sectoral tenets of community-based rehabilitation $(C B R)^{12}$. As a strategy for community development, the principles of CBR target the social determinants of mental health and in so doing advance structural and attitudinal changes in the society so that the social inclusion and disability rights of persons with an SMD are promoted ${ }^{13}$. Despite progressive policy frameworks, the primary mental health care services in South Africa are still dominated by a clinical recovery orientation ${ }^{14}$. Inadequate resourcing is preventing a change in service philosophy towards personal recovery, and infrastructure towards community-based interventions including $\mathrm{CBR}^{4}$.

Residential-based rehabilitation programmes were introduced in the Western Cape Province in 2008 to provide MHSUs with medical care, group-based psychoeducation, psychotherapy, and life skill training ${ }^{15}$. There remains limited information on the contribution that these programmes make to the recovery and community integration of persons with SMDs. The paucity of local research on psychosocial rehabilitation services in South Africa has been reported on ${ }^{16}$ and recent research has focussed on day centres ${ }^{17}$ as opposed to in-patient programmes. The aim of this study was therefore to investigate the perspectives of male MHSUs with SMD on the contribution that a six to nine-month residential-based rehabilitation programme made to their community integration. The purpose of the study was to inform the continuum of care for people with SMDs to better align residential-based rehabilitation and primary care public mental health services with the recovery needs of MHSUs.

\section{METHODOLOGY}

\section{Research context}

Gateway (pseudonym) was one of two 40-bed step-down/step-up residential-based rehabilitation facilities that were initiated in the Western Cape Province in 2008 as part of health system policy reforms. Step down refers to referral from a psychiatric hospital to the residential-based rehabilitation service and step up to referral from a $\mathrm{CHC}$ to a residential-based rehabilitation service. Admission to Gateway was voluntary with the average length of stay ranging between three-nine months. MHSUs develop strong relational ties with the out-patient clinic staff of the referring psychiatric hospital during this period. The Gateway service, headed by a social worker and staffed by a multi-professional psychiatric team, offered a groupbased weekly programme consisting of 14 group activities and eight themed projects addressing topics such as psychoeducation, treatment adherence, self-care, activities of daily living, creative exploration, and social integration skills. The programme followed a I2-week cycle after which themes were repeated.

After discharge, MHSUs return to their prior homes or, in some cases, to a supported living group home. Group home services are provided by non-profit organisations (NPOs), but long wait- ing lists and high financial costs make it an inaccessible option for many MHSUs, most of whom subsist on a monthly disability grant which, at the time of the study in 2015 was ZAR I350/US\$92 and is currently ZARI860/US\$I26I8. Aligned with the primary health care $(\mathrm{PHC})$ approach, the Gateway discharge policy stated that "the patient will be referred to the nearest community health clinic (CHC) and obtain at least one month's supply [medication] from the clinic before discharge, as part of the reintegration programme" 15:2. MHSUs were expected to develop new relationships with medical staff at their local CHC. Most persons admitted to Gateway lived in communities characterized by poverty, a high unemployment rate, gangsterism and substance abuse" .

\section{Study design and Ethics}

A qualitative, instrumental case study design ${ }^{19}$ was used to investigate male MHSUs' perspectives on the contribution of the Gateway programme to their community integration. The case enabled knowledge to be constructed about the instrumental interaction between residential-based rehabilitation and recovery-orientated community integration ${ }^{20}$. Ethics approval was obtained from the University of Cape Town Research Ethics Committee (HREC REF 582/20I3) and the Western Cape Department of Health Impact Assessment Unit (RP I56/20I3).

\section{Participant selection}

A sample size of five men was considered suitable for an instrumental case study ${ }^{19}$. Table I (p65) shows their demographic profiles. Participation in the study was voluntary with written informed consent by participants who were selected and recruited by key informants associated with Gateway in consultation with the researcher (first author). Participants were selected if they:

- had been to Gateway at least one year before the study (one year was deemed a suitable minimum period to experience community integration, given the protracted nature of recovery ${ }^{2 !}$ ).

- $\quad$ were male, aged between 18 and 55 years.

- had an SMD diagnosis.

- were apsychotic at the time of initial contact to give consent.

- spoke English or Afrikaans as their first or second language (translation cost restricted gathering data in other African languages).

- $\quad$ were willing to be interviewed more than once.

Participants were purposively selected using maximum variation sampling to reflect diverse dimensions of the instrumental case that were identified through the literature review. Variation was based on the following criteria:

- age (consideration was given to the age of onset of mental illness and chronological age).

- race (the racially based legacy of apartheid still resonates in the kind of life people can live ${ }^{22,23}$. White, African, and Coloured participants were included for variation).

- diagnosis of different mental disorders impact recovery in different ways).

- $\quad$ time since discharge from Gateway (one-year post-discharge was deemed adequate to allow for reflection on community integration).

- residential circumstances: where MHSUs live and whom they live with influence their mental health and well-being.

- employment history: consideration was given to the informal and formal sector given high unemployment rates in South Africa $^{24-26 .}$. 
Table I. Participants' demographics

\begin{tabular}{|c|c|c|c|c|c|c|c|c|}
\hline $\begin{array}{l}\text { Pseud- } \\
\text { onym }\end{array}$ & Age & Race & $\begin{array}{l}\text { Year of ad- } \\
\text { mission to } \\
\text { Gateway }\end{array}$ & Diagnosis & $\begin{array}{l}\text { Residential } \\
\text { circumstances }\end{array}$ & Employment & $\begin{array}{l}\text { Sub- } \\
\text { stance } \\
\text { use }\end{array}$ & $\begin{array}{l}\text { Gang } \\
\text { activity }\end{array}$ \\
\hline Mikaeel & 55 & Coloured & 2012 & Schizophrenia & Supported housing & Unemployed & No & No \\
\hline Bolo & 29 & Coloured & 2010 & Schizophrenia & $\begin{array}{l}\text { Overcrowded family } \\
\text { home on Cape Flats }\end{array}$ & $\begin{array}{l}\text { Informal some- } \\
\text { times illegal } \\
\text { income-generat- } \\
\text { ing activities }\end{array}$ & Yes & Yes \\
\hline Gershwin & 39 & Coloured & 2011 & $\begin{array}{l}\text { Bipolar Affective } \\
\text { Disorder }\end{array}$ & $\begin{array}{l}\text { Family home with } \\
\text { parents }\end{array}$ & Unemployed & Yes & No \\
\hline Emmanuel & 29 & Black & 2012 & Schizophrenia & $\begin{array}{l}\text { Informal settlement on } \\
\text { Cape Flats with family }\end{array}$ & Unemployed & Yes & No \\
\hline Dan & 27 & White & 2011 & $\begin{array}{l}\text { Schizo-affective } \\
\text { Disorder }\end{array}$ & Supported housing & $\begin{array}{l}\text { Informal ad hoc } \\
\text { jobs on building } \\
\text { sites }\end{array}$ & Yes & Yes \\
\hline
\end{tabular}

- $\quad$ substance use history: co-occurring substance abuse and mental disorders'.

- gang-related activity and its impact on crime and substance abuse were considered ${ }^{27,28}$.

- the number of previous admissions: participants varied in terms of years living with a mental illness and previous hospital admissions $^{8,16}$.

\section{Data Generation}

Data collection methods included document analysis, individual semi-structured interviews, resource mapping and a research jour$\mathrm{nal}^{20,29}$. A document analysis of programme and policy directives relevant to Gateway was undertaken to understand the intentions, structure, and content of the programme. Semi-structured interviews ${ }^{20}$ using questions based on a review of the personal recovery and community integration literature were conducted at the convenience of participants in secure and neutral environments with informed written and verbal consent. Resource mapping was used to identify support and service networks ${ }^{29}$. It involved drawing a visual layout of their various lived environments and then discussing what aspects of the programme they found helpful or not in promoting participation in the identified spaces and places after discharge. The researcher's reflective journal was used to triangulate the data. Due attention was paid to research ethics including patient rights throughout the data gathering process. Pseudonyms have been assigned to all facilities and participants to ensure anonymity.

\section{Data Management and Analysis}

Interviews were audio-recorded, transcribed verbatim and stored electronically. NVivo computer software ${ }^{30}$ was used to manage the data by first coding according to the study objectives and then sub-categorizing and categorizing the codes. Thematic withincase and cross-case analysis occurred by combining categories that were pertinent to the instrumentality between the rehabilitation programme and subsequent community reintegration ${ }^{20}$. Reflexivity, member checking, peer debriefing, an audit trail and data triangulation assisted in ensuring the trustworthiness of the findings ${ }^{20}$. Multiple data sources allowed for thick descriptions across situations and returning findings to participants after data analysis ensured that participants' voices carried through in the representation of their stories. NVivo was used to store and organise audit trail elements such as: consent forms, transcripts, recordings, community maps, field work memos, peer review comments, member-checking comments, reflexive journal entries and photographs of interview sites.

Table II: Overview of findings

\begin{tabular}{|c|c|c|}
\hline Theme & Category & Sub-category \\
\hline \multirow[t]{3}{*}{ It's a catch-22 situation } & $\begin{array}{c}\text { Category I } \\
\text { It's not just what you call it }\end{array}$ & $\begin{array}{l}\text { We are all different } \\
\text { Learning to live with a mental illness } \\
\text { Individual needs matter } \\
\text { Caregiver support helps or hinders progress }\end{array}$ \\
\hline & $\begin{array}{c}\text { Category } 2 \\
\text { There is no one size for all }\end{array}$ & $\begin{array}{l}\text { All we need is time } \\
\text { Policy dictates service } \\
\text { Programme content is not relevant to all }\end{array}$ \\
\hline & $\begin{array}{c}\text { Category } 3 \\
\text { It's tricky choosing between places } \\
\text { to go and things to do }\end{array}$ & $\begin{array}{c}\text { Weighing up disclosure } \\
\text { Health compromising occupations } \\
\text { Looking to the future }\end{array}$ \\
\hline
\end{tabular}




\section{FINDINGS}

Table II (p65) presents an overview of the central theme 'It's a catch-22 situation' along with the three categories within it. The subcategories are also included.

\section{Theme: "It's a catch-22 situation"}

The instrumental interaction between the residential-based rehabilitation and community re-integration created a catch-22 predicament for the men. They reported a paradoxical situation from which they could not escape because of contradictory limitations located firstly in the nature of their illness (category I: "it's not just what you call it"); secondly in the nature of the rehabilitation programme (category 2: "there is no one size for all") and thirdly, in the nature of community integration (category 3: "tricky choosing between places to go and things to do"). Although their Gateway experience aided their clinical recovery by providing respite from stressors related to their illness, it limited their personal recovery by protecting them from learning how to manage the challenges of community re-integration.

"So, I mean I'm in a catch-22. I never asked for it [SMD] but I always get told that I should be grateful that l'm one of the lucky ones who got seen and got help [Gateway] but it [SMD] also has its weighing burdens that's not gonna get any lighter." (Gershwin)

\section{Category I: "It's not just what you call it"}

This category describes the catch 22 tensions that MHSUs experienced when treated as a homogenous group of patients with SMD. While they understood that a diagnosis allowed professionals to identify clinical recovery treatment options, they felt that it did not enable service providers to understand the subjective meaning that a particular form of mental illness held for the individual concerned; it did not capture the relational challenges living with an SMD held for the individual.

"You know it's difficult when one has a mental illness; it is very difficult to speak about belonging. I mean most people belong somewhere but people with mental illness tend to be displaced, they don't really fit in anywhere... This belonging, where do you fit in? Who are you? We are all different... So there's a whole lot of layers." (Mikaeel)

They disagreed with service providers attributing all their actions to their diagnosis.

"My diagnosis is bipolar, and I have manic episodes as I am led to believe. You know before I was diagnosed with bipolar, I could do 30 things at once and no one complained. Now I have bipolar and it's '...you can't do 30 things at once, you're manic'......" (Gershwin)

MHSUs reported that their individual recovery needs were not sufficiently attended to because SMDs take on different meanings and forms for different people:

"It takes 30 years to realise that [the meaning of a diagnosis]. Like in my case I have paranoid schizophrenia you know, so there is always suspicion and fear and that type of thing... It means different things to different people. My schizophrenia is not like yours; it's very different from person to person, so even though we have the same title (laughs) if you like, but it's very different." (Mikaeel)
The men felt caught between the need for care and the need to individuate from the family by taking on adult responsibilities as a personal recovery strategy at home. The tension of having an SMD and what this meant for the men and for the expectation's others had of them.

"I live with my mother and father...I am lazy. I don't clean up there at home, I don't cook; I don't do any of this stuff. My mother is already doing it for me, my clothes already washing it for me, food already cooked for me. All these things. I can't say ok this l'm gonna do." (Emmanuel)

"What I want to say is that you are stuck in the relationship of an extended childhood for two reasons. The one is it's more than likely that your parents have put you inside an institution, so they have rights over you, which means that they control you because you are still staying under their roof which is where you'll find yourself because your life is getting interrupted... your accommodation, you are not working, so you become dependent on them. So, it's a vicious circle." (Gershwin)

\section{Category 2: 'There is no one size for all'}

A homogenised public mental health system offering a standardised PHC service structure and rehabilitation package created catch 22 tensions. Participants view the PHC model of mental health service as attending to the assumed needs of the collective by emphasising geographic convenience is important for everyone. The men reported that the long waiting times and unfamiliarity of service providers at the $\mathrm{CHCs}$ hindered their use of follow up services:
"Unhappiness starts in [suburb] day hospital [CHC]. You wait there four, five, six hours; that's with service and eight hours without service... or go to [tertiary psychiatric institution] where you see a psychologist and psychiatrist and collect your medication at the dispensary because it's a lot faster than if you went to [suburb] day hospital..." (Gershwin)

Paradoxically, the men wanted respite from the pressures of community living that the rehabilitation period provided but resented the demands that the structure and content of the programme placed on them.
"Space is very important; it gave me time away. If anything, that is what Gateway gave to me. And six months is an ok time to get that. There were niggling issues; I had to pee in a cup every morning (urine test) and other nonsense." "... six o'clock in the morning, there's no one else of your friends at home that they're getting up to shower and do those things. It's only you... So, by eight o'clock [evening] you're basically in bed and I mean for people who are 40 years old and whatever, and there are people of various ages there. They don't necessarily want to be you know, be managed..." (Gershwin)

The pressure of attending groups created catch 22 tensions from which they could not escape because of contradictory limitations:

\footnotetext{
"My illness made me very solitary in the sense that I like being on my own, you know, and what they do is you're kinda contained so you have to do it. You can't actually sit back and say no I don't want to do this. You have to participate in the programme, you
} 
know. So, it's hectically interactive because you're in groups all the time." (Mikaeel)

The men perceived some of the homogenised programme activities as decontextualised from the occupations they required for community integration such as looking for and holding down a job and disclosing their health status to prospective employers.

"They did little things like write out your CV [curriculum vitae] and stuff like that, but if they had a drive to get people jobs then we would've spent three days looking for jobs, not a session plucking out pictures from a YOU magazine, sticking it down with gum. It would've been a concerted effort to get these people into jobs." (Gershwin)

"I also don't like the part of getting to interviews because it gets me to the part of wondering about when they ask about employment: "What did you do and why did you leave the job?" So, when I come to that part about why did you leave the job? Because if I show you my CV, there are many things that I did, there were many jobs but at the same time I didn't spend long enough by the jobs through my illness so when it's like that then it's kinda difficult." (Emmanuel)

The perceived inflexibility of the programme meant forfeiting work opportunities during the rehabilitation period, including casual jobs secured through informal community networks.

"I had an opportunity to actually have a job while I was in the programme. What happened was Gateway and the social worker says that I wasn't fit to actually work. If I had an opportunity to, I would have earned a lot of money but it would have been too much of an actual disturbance to the set working programme for me not to be a part of the group once a day and just come back there and sleep at night time." (Dan)

"I just do garden work for people there in our street...I deliver wood... Once in three months, or once a month. I must check myself if there's work." (Bolo)

\section{Category 3: "It's tricky choosing between places to go and things to do"}

The complexity of the choices MHSUs are faced with when attempting to integrate into their communities is described in the category. MHSUs participation in occupations of choice promotes a sense of belonging and integration, but their options are severely constrained by structural elements and contexts in which either put them at risk of relapse or holds the delicate possibility of preventing it.

"As far as I'm concerned, I am integrated. I'm not overreaching. I'm taking what l've got and trying to make the most of that. I'm not imagining being here or there, just taking what l've got. I would say it is basically getting along with and being part of something." (Mikaeel)

MHSUs also expressed difficulties related to the temporal aspects of their community integration.

"It's only when the day goes by and then maybe I have to face another day, especially not in the house, but go somewhere, but then I leave my house and go somewhere else. I leave my house because they are not supportive, especially my father." (Emmanuel)

Being able to resist the temptation to smoke and drink through changing their routine is a strategy employed by MHSUs to avoid exposure to his relapse triggers. For Dan, his socialisation options become more limited because his relapse trigger is alcohol, which is readily available in the mainstream socialising spaces he frequents.

"So, I'm not allowed to drink any alcohol and what I do like doing is playing pool and l'm really good at it. Sometimes we go to the uhm, pubs and, and challenge the people to play pool. We do drink water and what happened on Saturday night we asked the bar lady if they have a jug of water and she said, no, no ways, this is an alcohol-drinking bar and you only come here to drink alcohol. So, we walked out and decided not to play there... No, there aren't pool tables with no alcohol... and like you can easily get influenced into drinking." (Dan)

Dan has to be firm in his decision not to abuse substances because he stands to lose his place in Safe House, an NPO- run supported living home.

There is tension between occupations that are available and have the capacity or inclination to access opportunities as they arise. In summation, 'It's tricky choosing between places to go and things to do' reflects important data on the inflexibility of structural elements, which frame personal occupational choices in the current environments of MHSUs.

\section{DISCUSSION}

The findings suggest that better alignment between residentialbased rehabilitation, community public mental health services and the recovery needs of MHSUs with SMD may be promoted firstly through residential-based rehabilitation programmes adopting a recovery approach; secondly through individualized, long term community-based recovery support and thirdly by helping MHSUs to participate in daily life through constructive time-use including access to paid or volunteer work.

\section{Rethinking residential-based rehabilitation}

The Gateway programme followed a standardized rehabilitation course informed by a medical model of care aimed at symptom reduction and functional skills training ${ }^{14}$. These dimensions of care are helpful in the post-acute stage of clinical recovery because they provide respite from the stressors of life, promote a stable mental state and equip MHSUs with skills for living with a chronic mental illness ${ }^{15}$. A medical model focus is insufficient to promote well-being and community integration for $\mathrm{MHSUs}^{21}$. A personal recovery model of care goes beyond standardised approaches to rehabilitation. It also considers the different environments within which the individual wants or needs to participate post-discharge and proactively addresses the dynamic interactions between the two as part of a personalised rehabilitation process ${ }^{21}$.

Similar to other studies, the MHSUs wanted a residential-based programme that afforded them gradual, graded exposure to community re-integration opportunities ${ }^{31}$. The findings indicate that person-specific factors such as hope, self-determination, agency, meaning and potential must be addressed throughout the rehabilitation process with due consideration of the sociocultural, economic and structural realities of the person's life including relational dynamics 
with family, friends, employers, community and society at large ${ }^{2,21}$. Involving MHSUs in constructing personally relevant recovery plans would align the content of the programme with their community integration needs. From an occupational therapy perspective, this means enabling MHSUs to gradually re-engage with things that matter in their lives as their mental state improves ${ }^{32-34}$.

Admission to Gateway was an occupational disruption in that it interfered with MHSUs' abilities to participate in, and benefit from, self-directed health-promoting occupations. Occupational disruptions result from a health condition or social circumstances which disturb a person's ability to engage in or benefit from occupations that hold personal meaning in terms of the roles, position, space and place that they occupy beyond the confines of the institution ${ }^{35}$. Occupational disruptions meant that the men's time use routine in the Gateway programme was disconnected from their community routines. The benefits of occupation for personal recovery such as routine, skill acquisition, purpose, competence, productivity and pleasure may be operationalised during rehabilitation through individualized time use goals ${ }^{36}$. Seamless synchronicity of occupational therapy services across the levels of care requires that residential based respite, reflection, and skills development include opportunities to engage in the everyday world ${ }^{31,34}$. The step-down rehabilitation programme should therefore be flexible enough to enable the gradual achievement of recovery goals through seamless synchronicity of services between the levels of mental health care.

\section{Rethinking community-based recovery support}

The community integration scenarios shared by the five MHSUs highlighted the need for support from the same service providers throughout the clinical recovery journey, especially at $\mathrm{CHC}$ medication collection points. Personal recovery would benefit from similar longitudinal relational support from members of the district mental health teams in the communities where MHSUs reside ${ }^{37}$. The findings suggest that recovery goals should be co-constructed, adapted when the need arises and monitored through a partnership between the MHSU, the residential rehabilitation team and the relevant primary level district mental health team. The latter working through task shifting to mental health trained community health workers who are positioned to build long term relationships with MHSUs with SMDs ${ }^{38}$. Task-shifting requires that tasks be redistributed among health workforce teams. Where appropriate, specific tasks are moved from highly qualified health workers to health workers with shorter training and fewer qualifications to make more efficient use of the available human resources for health $^{12,39}$. Capacitated in basic mental health promotion, the prevention of psychiatric disability and psychosocial community-based rehabilitation competencies and supervised by mental health and rehabilitation professionals, these workers would potentially close the current mental health service gap ${ }^{13}$.

The men in this study needed regular guidance to maintain their wellness during community integration. Community health workers with mental health, psychosocial community-based rehabilitation and psychiatric disability competencies would have made a difference in their community integration ${ }^{40}$. This cadre of worker is however not yet integrated into the human resource mix of the South African

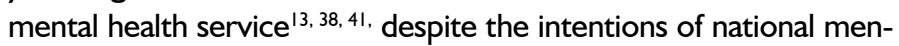
tal health, disability, and rehabilitation policies to close the mental health treatment gap ${ }^{42}$. Some progress has been made on task shifting psychotherapy competencies for common mental disorders from psychologists to lay counsellors ${ }^{39}$. Systems-thinking pertinent to community-based rehabilitation as an inter-sectoral strategy for community development, mental health promotion and prevention of disability arising from SMDs, is required to optimise task-shifting using lay providers ${ }^{40}$. Occupational therapy is in essence a systemsorientated health profession ${ }^{41}$. As a scarce human resource and as members of district mental health teams, occupational therapists are therefore positioned to operationalise population-level psychosocial CBR through task-shifting partnerships between MHSUs, community health workers upskilled in psychiatric disability and psychosocial rehabilitation as well as stakeholders in various public sectors ${ }^{43}$.

\section{Constructive time use, including work}

In the maelstrom of daily life, some men viewed having a mental illness as only one part of their identity, while others used it as the key definer of who they are. A sense of personal control and identity is central to MHSUs' ideas of what constitutes successful community life ${ }^{35}$. While a diagnosis affords access to treatment, it is also a source of stigma and social exclusion during community integration ${ }^{44}$. Participants were unanimous in that they did not carry their illness identity with them, yet it was the key identifier for their families and service providers in terms of gauging their potential for recovery. Similar to other studies, stigma, social exclusion and discriminatory practices did not allow them to fully participate in community living ${ }^{34,45}$. Despite contextual and socio-economic factors constraining their identity and occupational choices, the MHSUs self-regulated their level of engagement in everyday activities after discharge and, in so doing, perceived themselves to be integrated. From an occupational therapy perspective, the development of recovery orientated services therefore requires information about how MHSUs in historically marginalised communities spend their time and conduct their daily live $\mathrm{e}^{\mathrm{s} 31}$. Community integration will be promoted by focusing on occupational engagement and helping MHSUs organise their daily occupations ${ }^{31}$. It is at this junction that close collaboration between occupational therapists and community health workers becomes central to the successful community integration of MHSUs with SMDs.

None of the men were permanently employed at the time of the research nor was it likely that they would secure employment in the open labour market after discharge given the rate of unemployment on the Cape Flats ${ }^{28}$. The men employed a range of income-generating strategies to meet their financial needs in response to years of living and learning to cope with an SMD. They were 'street smart' in the Cape Flats context and knew how to secure informal work to survive economically ${ }^{24}$. Some of their coping strategies were acquired, reinforced, or, in the case of securing informal work opportunities, eroded during participation in the rehabilitation programme. Linking closely with community health workers in the communities where MHSUs reside will ensure closer alignment between the content of a residential rehabilitation programme and the occupational realities of their lives including informal income generation. People experience well-being when they can engage in occupations they need or want to do, in an environment which allows it, and when they have the physical, mental and social support to do so ${ }^{46}$. In particular, understanding the perspectives of men on the processes of community integration is valuable in sensitising clinicians to gender as a guiding factor in designing the content of rehabilitation programmes. In this way, occupational therapy can play a role in understanding which occupations are ideal, expected or appropriate for MHSUs and which ones exclude them ${ }^{24}$.

\section{CONCLUSION}

The findings from this study indicate that the community integration 
of men with SMDs is multidimensional and unique. The community integration scenarios shared by the five MHSUs highlighted the need for stable service providers throughout the recovery journey, especially at medication collection points. Residential-based rehabilitation services that focus on the treatment of symptomatology should consider the advantages of offering services which also offer long-term post-discharge relational support to facilitate graded community integration. A focus on occupation helps service providers and occupational therapists, in particular, to remain cognisant of the contexts that people with SMDs come from and return to, and, in so doing, provide programmes and services which are personalised, recovery-focused and flexible. Seamless handover between residential and community-based occupational therapy services ensures continuity of occupation-centred interventions that promote the social inclusion of persons with SMD by targeting their time use and enabling participation in health-promoting occupations. While the respite potential of residential-based rehabilitation services is clear, their role as an intermediary between institution and community integration remains nebulous.

\section{LIMITATIONS}

This study only focused on the perspectives of men. The experiences of women with SMD of residential-based rehabilitation, recovery, and community integration warrant investigation. The researcher was a female conducting research with men. Due to her position as an occupational therapist and researcher, there might have been power dynamics at play where participants could have felt that they needed to respond in a particular manner as they were being interviewed by a health practitioner. Although conversant in either English or Afrikaans, participants in the study who were first-language isiXhosa speakers may have struggled to convey their perspectives as clearly as they would have wanted to. When Gateway was relocated back to the tertiary hospital in 2017 it became a recovery unit for service users living with SMD and comorbid substance use disorders. The findings from this study can still inform the programme content to align it with the diverse needs of service users, even if it is no longer located in the community. Furthermore, the insights into community integration may have relevance to mental health programmes beyond residential-based, intermediate facilities.

\section{FUNDING}

Research funding was provided by Cannon Collins Trust and the University of Cape Town Research Office

\section{ACKNOWLEDGEMENTS}

The authors would like to acknowledge the mental health service users as experts by experience who so generously participated in the study and shared their stories to give voice to their experiences of rehabilitation and community integration.

\section{ROLE OF AUTHORS}

Fadia Gamaldien is the first author and principal investigator. She completed the research as part of her master's in occupational therapy degree at the University of Cape Town and prepared the manuscript for publication. Madeleinde Duncan and Roshan Galvaan supervised the research project and contributed to the conceptualisation of the manuscript. All three authors contributed to finalising the manuscript prior to publication.

\section{REFERENCES}

I. Whiteford HA, Ferrari AJ, Degenhardt L, Feigin V, Vos T. The global burden of mental, neurological and substance use disorders: an analysis from the Global Burden of Disease Study 2010. PLoS One. 20I5; I0(2). https://doi.org/I0.1596/978-I-46480426-7_ch2

2. Aldersey HM, Adeponle AB, Whitley R. Diverse Approaches to Recovery from Severe Mental IIIness. The Palgrave Handbook of Sociocultural Perspectives on Global Mental Health; 2017:109. 27. https://doi.org/10.1057/978-I-137-395 I0-8_6

3. Kessler RC, Aguilar-Gaxiola S, Alonso J, Chatterji S, Lee S, Ormel J, et al. The global burden of mental disorders: An update from the WHO World Mental Health (WMH) Surveys. Epidemiology and Psychiatric Sciences. 2009; 18(I):23-33.

https://doi.org/10.1017/s1/21189×00001421

4. Vigo D, Thornicroft G, Atun R. Estimating the true global burden of mental illness. Lancet Psychiatry. 2016;3(2): I 7 I-8. https://doi.org/10.1016/s2215-0366(15)00505-2

5. Petersen I, Ssebunnya J, Bhana A, Baillie K. Lessons from case studies of integrating mental health into primary health care in South Africa and Uganda. International Journal of Mental Health Systems. 20I I;5:8. https://doi.org/I0. I I86/I752-4458-5-8

6. Lund C, Kleintjes S, Cooper S, Petersen I, Bhana A, Flisher AJ, et al. Challenges facing South Africa's mental health care system: stakeholders' perceptions of causes and potential solutions. International Journal of Culture and Mental Health. 20I I;4(I):23-38 https://doi.org/ I0.1080/17542863.2010.503039

7. Kohn R, Saxena S, Levav I, Saraceno B. The treatment gap in mental health care. Bulletin of the World Health Organization. 2004;82(I I):858-66.

7. Radomski MV, Latham CAT. Occupational therapy for physical dysfunction: Lippincott Williams \& Wilkins; 2008.

8. Slade M. Personal recovery and mental illness: A guide for mental health professionals: Cambridge University Press; 2009.

9. Anthony WA. Recovery from mental illness: the guiding vision of the mental health service system in the 1990s. Psychiatr Rehabil J. 1993; I6(4): I I.https://doi.org/ I0.1037/h0095655

10. Ellison ML, Belanger LK, Niles BL, Evans LC, Bauer MS. Explication and definition of mental health recovery: A systematic review. Administration and Policy in Mental Health and Mental Health Services Research. 2018;45(1):91-102. https://doi.org/ I0.1007/s 10488-0 16-0767-9.

II. Gillis L, Robertson BA, Zabow T, Stein DJ. No health without mental health: Establishing psychiatry as a major discipline in an African faculty of health sciences. SAMJ: South African Medical Journal. 20 I2; 102(6):449-5 I. https://doi.org/I0.7I 96/SAMJ.5449.

12. World Health Organization. The optimal mix of services for mental health: WHO pyramid framework. Geneva: World Health Organization. 2005. https://doi.org// 0.1596/978-I-4648-04267_ch I I

13. Brooke-Sumner C, Lund C, Selohilwe O, Petersen I. Communitybased psychosocial rehabilitation for schizophrenia service users in the north-west province of South Africa: A formative study. Social Work in Mental Health. 2017;15(3):249-83. https://doi.org/10.1080/15332985.2016.1220439

14. Parker JS. Developing the philosophy of recovery in South African mental health services. African journal of psychiatry. 20I2; 15(6). https://doi.org/I0.43 I4/ajpsy.v15i6.5 I

15. Associated Psychiatric Hospital. Step down/ Step up facilities in the Western Cape Metro. Cape Town Associated Psychiatric 
Hospital; 2008.

16. Kramers-Olen AL. Psychosocial rehabilitation and chronic mental illness: international trends and South African issues. South African Journal of Psychology. 2014;44(4):498-5 I 3

https://doi.org/10.1 I77/008 I2463 |4553339

17. Ramafikeng M, Beukes L, Hassan A, Kohler T, Mouton TL, Petersen S. Experiences of adults with psychiatric disabilities participating in an activity programme at a psychosocial rehabilitation centre in the Western Cape. South African Journal of Occupational Therapy. 2020;50(2):44-5I http://doi.org/10.17/59/2310-3833/2020/vol50no2a6

18. South African Social Security Agency. You and your grants 20I4/20I5. SASSA; 2014.

https://pmg.org.za/committee-meeting/2 I618/ [ 17 June 2020]

19. Stake RE. Multiple case study analysis: Guilford Press; 2006.

20. Creswell JW, editor. Qualitative inquiry and research design: Choosing among five approaches Thousand Oaks, CA: Sage; 2007.

21. Drake RE, Whitley R. Recovery and severe mental illness: description and analysis. The Canadian Journal of Psychiatry. 20।4;59(5):236-42.

https://doi.org//0.1 I77/07067437| 405900502

22. Coovadia H, Jewkes R, Barron P, Sanders D, Mclntyre D. The health and health system of South Africa: historical roots of current public health challenges. The Lancet. 2009;374(9692):81734.

https://doi.org/10.1016/S0140-6736(09)6095I-X

23. Mayosi BM, Lawn JE, van Niekerk A, Bradshaw D, Abdool Karim SS, Coovadia HM. Health in South Africa: changes and challenges since 2009. The Lancet. 20I2;380(9858):2029-43. https://doi.org/10.1016/S0140-6736(12)61814-5

24. Gamieldien F, van Niekerk L. Street vending in South Africa: An entrepreneurial occupation. South African Journal of Occupational Therapy. 2017;47(I):24-9.

https://doi.org/10.17/59/2310-3833/2017/vol47nla5.

25. Kleintjes S, Lund C, Swartz L. Barriers to the participation of people with psychosocial disability in mental health policy development in South Africa: a qualitative study of perspectives of policy makers, professionals, religious leaders and academics. (Report). BMC International Health and Human Rights. 2013;13(I).

https://doi.org/10.1186/1472-698X-13-17

26. Roever S. Informal trade meets informal governance: Street vendors and legal reform in India, South Africa, and Peru. Cityscape. 2016;18(1):27-46

https://www.jstor.org/stable/26328239

27. MacMaster LL. Social and economic emasculation as contributing factors to gangsterism on the Cape Flats. Scriptura: Journal for Contextual Hermeneutics in Southern Africa. 2007;95(I):278-89.

https://doi.org// 0.7833/95-0-1403.

28. Bowers Du Toit NF. Gangsterism on the Cape Flats: A challenge to 'engage the powers'. HTS Teologiese Studies / Theological Studies. 2014;70(3) https://doi.org/10.4102/hts.v70i3.2727

29. Rossler W. Psychiatric rehabilitation today: an overview. World Psychiatry. 2006;5(3): I51-7

30. Castleberry A. NVivo 10 [software program]. Version I0. QSR International; 2012. Am J Pharm Educ. 2014;78(I). https://doi.org/ 10.5688/ajpe78I 25

31. Kelly M, Lamont S, Brunero S. An Occupational Perspective of the Recovery Journey in Mental Health. Br J Occup Ther.
2010;73(3): 129-35.

https://doi.org//0.4276/0308022 I0x| 2682330090532

32. Soundy A, Stubbs B, Roskell C, Williams SE, Fox A, Vancampfort $D$. Identifying the facilitators and processes which influence recovery in individuals with schizophrenia: a systematic review and thematic synthesis. Journal of Mental Health. 2015;24(2): 103-10

https://doi.org/10.3109/09638237.2014.9988। I

33. Sutton DJ, Hocking CS, Smythe LA. A phenomenological study of occupational engagement in recovery from mental illness. Can J Occup Ther. 2012;79(3): I42-50

https://doi.org/10.2182/cjot.2012.79.3.3

34. Tew J, Ramon S, Slade M, Bird V, Melton J, Le Boutillier C. Social factors and recovery from mental health difficulties: a review of the evidence. Br J Soc Work. 2012;42(3):443-60 https://doi.org/10.1093/bjsw/bcr076

35. Krupa T, Fossey E, Anthony WA, Brown C, Pitts DB. Doing daily life: How occupational therapy can inform psychiatric rehabilitation practice. Psychiatric Rehabilitation Journal. 2009;32(3): 155 https://doi.org/10.2975/32.3.2009.155.16I

36. Iyer SN, Mangala R, Anitha J, Thara R, Malla AK. An examination of patient-identified goals for treatment in a firstepisode programme in Chennai, India. Early Interv Psychiatry. $2011 ; 5(4): 360-5$.

https://doi.org/10.1 I I I/j. I75I-7893.201 I.00289.x

37. Banfield $M$, Forbes $O$. Health and social care coordination for severe and persistent mental illness in Australia: a mixed methods evaluation of experiences with the Partners in Recovery Program. Int J Ment Health Syst. 2018; 12:13.

https://doi.org/I0.1 I86/s I3033-018-0194-2

38. Sibeko G, Milligan PD, Roelofse M, Molefe L, Jonker D, Ipser J, et al. Piloting a mental health training programme for community health workers in South Africa: an exploration of changes in knowledge, confidence and attitudes. BMC Psychiatry. $2018 ; 18(1)$.

https://doi.org/10.1 I86/s I 2888-018-1772-I

39. Spedding MF, Stein DJ, Sorsdahl K. Task-shifting psychosocial interventions in public mental health: A review of the evidence in the South African context. South African health review. 20I4;20I4(I):73-87

40. Javadi D, Feldhaus I, Mancuso A, Ghaffar A. Applying systems thinking to task shifting for mental health using lay providers: a review of the evidence. Global Mental Health. 2017;4 https://doi.org/10.1017/gmh.2017.15

4I. Gilmore B, MacLachlan M, McVeigh J, McClean C, Carr S, Duttine $A$, et al. A study of human resource competencies required to implement community rehabilitation in less resourced settings. Human resources for health. 2017; I5(1):70. https://doi.org/10.1 I86/s I 2960-017-0240-I

42. Dept. of Health. National mental health policy framework and strategic plan 20I3-2020. 20 I4.

43. Ned L, Tiwari R, Buchanan H, Van Niekerk L, Sherry K, Chikte $U$. Changing demographic trends among South African occupational therapists: 2002 to 2018 . Human Resources for Health. 2020; I 8(I). https://doi.org/10.1 186/s I2960-020-0464-3

44. Howe L, Tickle A, Brown I. 'Schizophrenia is a dirty word': service users' experiences of receiving a diagnosis of schizophrenia. The Psychiatric Bulletin. 2014;38(4): I54-8. https://doi.org/10.1192/pb.bp. I13.045179

45. Pereira RB, Whiteford GE. Understanding social inclusion as an 
international discourse: implications for enabling participation.

Br J Occup Ther. 20 I 3;76(2): I I 2-5.

https://doi.org//0.4276/0308022 I 3x/36032444/9392

46. Wilcock AA. An occupational perspective of health: Slack Incorporated; 2006.

\section{Corresponding Author}

\section{*Fadia Gamieldien}

Email: fadia.gamieldien@uct.ac.za 